\title{
Influence of Climate, Variety and Production Process on Tocopherols, Plastochromanol-8 and Pigments in Flaxseed Oil
}

\author{
Marko Obranovići ${ }^{1 *}$, Dubravka Škevin ${ }^{1}$, Klara Kraljić1 ${ }^{1}$ Milan Pospišil ${ }^{2}$, \\ Sandra Neđeral ${ }^{1}$, Monika Blekić ${ }^{1}$ and Predrag Putnik ${ }^{1 *}$ \\ ${ }^{1}$ Faculty of Food Technology and Biotechnology, University of Zagreb, Pierottijeva 6, HR-10000 Zagreb, Croatia \\ ${ }^{2}$ Faculty of Agriculture, University of Zagreb, Svetošimunska cesta 25, HR-10000 Zagreb, Croatia \\ Received: May 12, 2015 \\ Accepted: June 2, 2015
}

\begin{abstract}
Summary
The objective of this study is to compare the influence of genotype, environmental conditions and processing methods after maturation and harvesting of four varieties of flaxseed (Altess, Biltstar, Niagara and Oliwin) on the levels of tocochromanols, carotenoids and chlorophyll in flaxseed oil. Samples were produced by cold pressing of dry seeds and seeds heated for $30 \mathrm{~min}$ at $60^{\circ} \mathrm{C}$. Temperature, sunshine and rainfall were primary environmental conditions included. Grand mean of mass fraction of $\gamma$-tocopherol was (522 \pm 29 ), of plastochromanol-8 (305 \pm 2 ) and total tocochromanols $(831 \pm 3) \mathrm{mg}$ per $\mathrm{kg}$ of oil. The highest levels of these compounds and strongest antioxidant activity were found in cold-pressed oil of Biltstar variety. During seed maturation, levels of $\gamma$-tocopherol and plastochromanol-8 increased with average temperature and total sunshine and decreased with total rainfall. Fifth week after flowering was identified as the maturation period with best climate conditions to achieve optimal tocochromanol content. Grand mean of mass fraction of carotenoids expressed as $\beta$-carotene was $(1.83 \pm 0.01)$ and of chlorophyll expressed as pheophytin a $(0.43 \pm 0.10) \mathrm{mg}$ per $\mathrm{kg}$ of oil. Altess variety had the highest levels of pigments. Antioxidant activity decreased with the increase of chlorophyll, while correlations with carotenoids were not determined. Generally, oil obtained by cold pressing had higher levels of tocochromanols and lower levels of pigments but similar antioxidant activity to the oil after seed conditioning. The results of this study contribute to identifying the flaxseed variety that is the best for oil production with the highest antioxidant activity and nutritive value, and provide better understanding of tocochromanol biosynthesis depending on different climate conditions.
\end{abstract}

Key words: flaxseed oil, variety, cold pressing, conditioning, tocopherols, plastochromanol-8, carotenoids, chlorophyll, climate

\section{Introduction}

Flaxseed oil contains more than $50 \%$ of $\alpha$-linolenic acid and more than $13 \%$ of linoleic acid, which makes it very susceptible to oxidation and taste deterioration (1). Antioxidants help protect flaxseed oil from oxidation. The primary antioxidants in flaxseeds are tocochromanols, a group that consists of four tocopherols $\left(\alpha_{-}, \beta_{-}, \gamma^{-}\right.$and $\left.\delta_{-}\right)$ and four tocotrienols $(\alpha-, \beta-, \gamma-$ and $\delta-)$. As reported in other studies, quantities of tocopherols in flaxseed oil significantly differ from 154 to $934 \mathrm{mg} / \mathrm{kg}$ of oil with the main representative $\gamma$-tocopherol $(1,2)$. Such big variations could be a result of different harvesting locations and varieties, extraction technologies or storage time of packed flaxseed oil. 
Plastochromanol-8 is considered as natural homologue of $\gamma$-tocotrienol and second most represented tocochromanol in flaxseed with more than $25 \%$ out of total tocochromanols (3). Recently, its antioxidant capacity has been documented to be similar to that of $\gamma$-tocotrienol and 1.5 times higher than of $\alpha$-tocopherol (3). Various plants and oilseeds have shown extreme variations in the mass fractions of tocopherols and other antioxidants in their fat and oil content, which also differed depending on various cultivars and geographical location $(4,5)$. Herchi et al. (6) reported detailed analysis of lipid biosynthesis in flaxseed from flowering to full maturity, which lasted approx. 56 days. The most intensive biosynthesis of oil happened between 7 th and 42nd day after flowering, after which the oil content slightly decreased until harvesting time. In comparison with another work by Herchi et al. (7) on tocochromanol biosynthesis in flaxseed, it is noticeable how these compounds follow similar path, indicating that tocochromanols have the main role as seed antioxidants. Other important antioxidants in flaxseed are carotenoids, which are members of a larger group of plant pigments with 750 different structures (8). They function as hormone precursors, colourants and essential elements in photosynthetic cycle (8). In some cases, specific carotenoids are essential for mammalian diets as precursors for vitamin A synthesis. Carotenoids, having a highly conjugated double bonds, are known to act as antioxidants by trapping the hydroperoxide intermediates and stopping the chain reactions in autoxidation. Both carotenoids and tocochromanols are synthesized partially or entirely as plastidic isoprenoids during biosynthetic pathway (8).

The influence of climate on flaxseed oil content has not been clarified yet. A few studies have shown that flaxseed development, processing and variety influence the characteristics of flaxseed oil (content of tocochromanols and pigments) $(2,7,9,10)$. However, these studies observed that the oil samples were obtained from one harvesting year, therefore providing a skewed view of how climatic factors associate with oil characteristics. Furthermore, there is no published data that combines different varieties, production processes with climate factors and their cumulative influence on tocochromanols, and the pigment content in flaxseed oil.

Flaxseed oil production was positioned 11th in 2013 with $564818 \mathrm{t}$ of global vegetable oil production. The main producers were China, India, Germany, Canada, Italy and Egypt, covering different continents and climate areas (11). Its long history of cultivation in different regions resulted in vast botanical flaxseed diversity. For instance, Canada and EU combined, listed 223 different flaxseed varieties $(12,13)$.

Information on chemical composition of particular flaxseed varieties opens a possibility for different blends of produced oil with the aim of improving their nutritional and sensory value and oxidation stability. Similar research was done on extra virgin olive oil (14).

The objective of this study is to compare the influence of genotype, environmental conditions (temperature, sunshine hours and rainfall) and processing methods after maturation of four varieties of flaxseed (Altess, Biltstar, Niagara and Oliwin) on the levels of carotenoids, chlorophyll and tocochromanols in flaxseed oil.

\section{Materials and Methods}

\section{Flaxseed and sampling conditions}

Three brown flaxseed varieties (Altess, Biltstar and Niagara) and one golden variety (Oliwin) were used in experiments. Cultivars were grown for three years (between 2011 and 2013) on the experimental field of the Faculty of Agriculture, University of Zagreb, Croatia, at $120 \mathrm{~m}$ above sea level. All cultivars were sown in the first half of April and seeds were harvested when they reached harvesting maturity (mid to late July) determined by morphological markers that included pod and seed colour. Experiments were set up according to the randomized complete block design in five repetitions. Size of a plot was $6.6 \mathrm{~m}^{2}$. The soil of the experimental field Maksimir, Zagreb is anthropogenized eutric brown, on slightly luvic loam. Reaction of the soil in the plough layer was weakly acid $(1 \mathrm{M} \mathrm{KCl}$ had $\mathrm{pH}=6.29)$, it was poorly supplied with humus $(2.6 \%)$, well supplied with available phosphorus (39.9 mg of $\mathrm{P}_{2} \mathrm{O}_{5}$ per $100 \mathrm{~g}$ of soil) and medium supplied with available potassium (18.7 $\mathrm{mg}$ of $\mathrm{K}_{2} \mathrm{O}$ per $100 \mathrm{~g}$ of soil).

\section{Reagents}

All chemicals and solvents were of analytical grade, obtained from Carlo Erba Réactifs SdS (Chaussée du Vexin, France). The 2,2-diphenyl-1-picrylhydrazyl (DPPH) radical was purchased from Sigma-Aldrich Co. (St. Louis, MO, USA). Tocopherols $(\alpha-, \beta-, \gamma-$ and $\delta-)$ were acquired from Merck KGaA (Darmstadt, Germany). Plastochromanol-8 was provided by Dr Jerzy Kruk from Jagiellonian University, Kraków, Poland.

\section{Oil extraction}

Oil was extracted within 40 days after harvesting of each cultivar by two methods: cold pressing of dry seeds (15) or heating the seeds for $30 \mathrm{~min}$ at $60^{\circ} \mathrm{C}$. A mass of 700 $\mathrm{g}$ of freshly ground flaxseed was used in both methods. Cold-pressed oil was treated at a temperature $\leq 50{ }^{\circ} \mathrm{C}$, while heat-treated flaxseeds were first heated with the addition of $80 \mathrm{~mL}$ of water (divided in three parts; one third added at the beginning, one after $15 \mathrm{~min}$ and one at the end) and constant stirring in a tray at $60{ }^{\circ} \mathrm{C}$ for $30 \mathrm{~min}$, and then immediately pressed. Both types of oil were pressed using a laboratory screw press Komet CA/53 (Monforts and Reiners, IBG, Mönchengladbach, Germany). The oil was filtered through a sintered glass filter (10-16 $\mu \mathrm{m}$ pore size) and stored at room temperature in dark bottles with nitrogen until analysis. All analyses were finalized in less than a month from oil production.

\section{Determination of tocochromanols using HPLC}

Tocochromanol content was determined according to ISO standard 9936:2006 (16) using normal-phase high-performance liquid chromatography (HPLC) analysis. Samples were prepared by dissolving $0.1 \mathrm{~g}$ of flaxseed oil in $10 \mathrm{~mL}$ of $n$-hexane and then analysed by HPLC equipped with a fluorescence detector and LiChroCART ${ }^{\circledR}$ Silica 60 column $(250 \mathrm{~mm} \times 4.6 \mathrm{~mm}$ i.d., particle size $5 \mu \mathrm{m}$; Merck, Darmstadt, Germany). Tocochromanols were detected at 295 and $330 \mathrm{~nm}$ excitation and emission wavelengths and 
separated by isocratic chromatography by mobile phase of $0.7 \%$ propan-2-ol in $n$-hexane at a flow rate of $0.9 \mathrm{~mL} /$ min. Analyses were performed at room temperature. Tocochromanols were quantified by standard calibration curves of $\alpha-, \beta-, \gamma$ - and $\delta$-tocopherols. Plastochromanol-8 was quantified using calibration curve of $\alpha$-tocopherol.

\section{Spectrophotometric analysis of pigments}

Pigments were determined spectrophotometrically. Total chlorophylls, expressed as pheophytin a, were determined using the method of Pokorny et al. (17) and by measuring the absorbance of the solution of oil against an air blank at 630, 670 and $710 \mathrm{~nm}$. Total carotenoids, expressed as $\beta$-carotene, were determined by measuring the absorbance of an oil solution in cyclohexane at $445 \mathrm{~nm}$ using the BS method 684-2.20:1977 (18). Eqs. 1 and 2 were used to calculate total chlorophyll and carotenoid content, respectively:

$$
\begin{gathered}
w(\text { total chlorophyll })=345.3 \cdot\left(\frac{A_{670 \mathrm{~nm}}-0.5 \cdot\left(A_{630 \mathrm{~nm}}+A_{710 \mathrm{~nm}}\right)}{L}\right) / 1 / \\
w(\text { total carotenoid })=\frac{383 \cdot A_{445 \mathrm{~nm}}}{L \cdot \mathrm{g}} / 2 /
\end{gathered}
$$

where 345.3 and 383 are conversion factors, $A$ is the absorbance at the specified wavelength, $L$ is the thickness of the glass cell $(\mathrm{cm})$ and $\gamma$ is the concentration $(\mathrm{g} / 100 \mathrm{~mL})$ of the solution of oil in cyclohexane.

\section{Radical scavenging activity of oil samples}

Radical scavenging activity was defined as the ability of oil to quench the stable 2,2-diphenyl-1-picrylhydrazyl (DPPH) radical. This method is commonly used to determine antioxidant capacity of oil. Reduction in the amount of free DPPH radical was determined by measuring the colour change of the reaction solution at $515 \mathrm{~nm}$ using a spectrophotometer and following the method described by Kalantzakis et al. (19). Briefly, $10 \%$ (by mass per volume) of the solution of oil in ethyl acetate $(1 \mathrm{~mL})$ was added to freshly prepared $0.125 \mathrm{mM}$ DPPH solution (4 $\mathrm{mL}$ ). The reaction mixture was shaken, kept in dark for 30 $\mathrm{min}$, and then the absorbance was measured against the blank solution (without DPPH radical). The DPPH concentration was calculated from calibration curve, and was used for calculating radical scavenging activity expressed as the percentage reduction in DPPH concentration by the oil constituents:

$$
\mathrm{DPPH} \text { reduction }=\left(1-\frac{c(\mathrm{DPPH})_{30}}{c(\mathrm{DPPH})_{0}}\right) \cdot 100
$$

where $c(\mathrm{DPPH})_{0}$ and $c(\mathrm{DPPH})_{30}$ are concentrations of $\mathrm{DPPH}$ in the control sample $(t=0 \mathrm{~min})$ and in the test mixture $(t=30 \mathrm{~min})$.

\section{Meteorological data}

Meteorological data were provided by Meteorological and Hydrological Service of Republic of Croatia for the exact location (Maksimir, Zagreb, Croatia; $45^{\circ} 49^{\prime} 0^{\prime \prime} \mathrm{N}$, $\left.16^{\circ} 02^{\prime} 00^{\prime \prime} \mathrm{E}\right)$. Data for sunshine $(\mathrm{h})$ and rainfall $(\mathrm{mm})$ were given as total daily values, and temperature as mean daily value $\left({ }^{\circ} \mathrm{C}\right)$.

\section{Statistical analysis}

Descriptive statistics was used to assess the basic information about the data. Contents of $\alpha$-tocopherol, plastochromanol-8, $\gamma$-tocopherol, $\delta$-tocopherol, total tocochromanols, chlorophyll and carotenoids were continuous dependent variables, while harvest year, flaxseed variety and type of pressing were categorical independent variables. Continuous variables were analyzed using three-way ANOVA. Pearson's linear correlation tested the relationship between the pairs of continuous variables. Marginal means were compared with least significant difference (LSD) multiple comparison tests. Principal component analysis (PCA) was used to calculate simultaneous association of selected climate variables (temperature, sunshine and rainfall). Appropriateness of this approach was evaluated by Kaiser-Meyer-Olkin measure of sampling adequacy that equaled to 0.7. All variables for PCA were standardized and formed the factor called climate index. Keiser rule was used for factor retention. Factor analysis score was obtained by linear regression. The significance levels for all tests were $\alpha \leq 0.05$, while analyses were performed with IBM SPSS Statistics v. 20 (IBM Corporation, Armonk, NY, USA).

\section{Results and Discussion}

The results showed flaxseed oil as a rich source of natural vitamin $E$ that changes significantly with different climate conditions during maturation, variety and type of oil production (Table 1).

\section{Maturation period, climate and climate index}

Flaxseeds were harvested in three consecutive years, 2011-2013, after maturation period of 45,49 and 48 days after flowering, respectively. For each year and full period of maturation three main climate parameters were measured, analyzed and compared. Values for climate parameters were evaluated on a weekly basis for easier comparison with previously published research on oil and tocochromanol biosynthesis in flaxseed. It can be concluded that 2012 had the highest average weekly temperature $\left(22.9^{\circ} \mathrm{C}\right)$ with the highest average weekly precipitation $(21.6 \mathrm{~mm}), 2011$ had the lowest average of total weekly sunshine $(59 \mathrm{~h})$ and 2013 had the lowest average weekly precipitation $(1.3 \mathrm{~mm})$ with the highest average of total weekly sunshine $(71 \mathrm{~h})$. To provide better understanding of the influence of climate on the studied bioactive compounds, we calculated climate index based on PCA analysis with combining all annual values of temperature, sunshine and rainfall for maturation period of flaxseed starting from the moment of flowering until harvesting. Equations needed for conversion of climate index were as follows:

$$
\begin{gathered}
\text { Temperature }=22.56+2.32 \cdot \text { climate index } \\
t(\text { sunshine })=10.05+1.58 \cdot \text { climate index } \\
h(\text { rainfall })=1.92-1.36 \cdot \text { climate index }
\end{gathered}
$$

Correlations of climate index with the content of individual/total tocochromanols and pigments with the percentage of DPPH reduction are shown in Table 2. For each 
Table 1. Composition of tocochromanols and pigments in flaxseed oil obtained in three harvesting years, from four varieties and with two types of pressing

\begin{tabular}{|c|c|c|c|c|c|c|c|c|}
\hline & \multicolumn{8}{|c|}{$w /(\mathrm{mg} / \mathrm{kg}$ oil $)$} \\
\hline & $\begin{array}{c}\alpha \text {-Toco- } \\
\text { pherol }\end{array}$ & $\begin{array}{l}\text { Plastochro- } \\
\text { manol-8 }\end{array}$ & $\begin{array}{l}\gamma \text {-Toco- } \\
\text { pherol }\end{array}$ & $\begin{array}{l}\delta \text {-Toco- } \\
\text { pherol }\end{array}$ & $\begin{array}{l}\text { Total } \\
\text { tocochro- } \\
\text { manols }\end{array}$ & Chlorophyll $^{1}$ & Carotenoids ${ }^{2}$ & $\begin{array}{c}\text { DPPH } \\
\text { reduction/\% }\end{array}$ \\
\hline \multicolumn{9}{|l|}{ Harvesting year } \\
\hline 2011 & $(1 \pm 1)^{\mathrm{a}}$ & $(265 \pm 3)^{a}$ & $(463 \pm 4)^{\mathrm{a}}$ & $(1.0 \pm 0.1)$ & $(732 \pm 5)^{\mathrm{a}}$ & $(0.43 \pm 0.01)^{\mathrm{a}}$ & $(1.39 \pm 0.01)^{\mathrm{a}}$ & $(59 \pm 0)^{\mathrm{a}}$ \\
\hline 2012 & $(1 \pm 1)^{\mathrm{a}}$ & $(282 \pm 3)^{b}$ & $(526 \pm 4)^{\mathrm{b}}$ & $\operatorname{tr}$ & $(809 \pm 5)^{b}$ & $(0.24 \pm 0.01)^{\mathrm{b}}$ & $(1.69 \pm 0.01)^{\mathrm{b}}$ & $(66 \pm 0)^{\mathrm{b}}$ \\
\hline 2013 & $(8 \pm 1)^{\mathrm{b}}$ & $(367 \pm 3)^{c}$ & $(575 \pm 4)^{c}$ & $\operatorname{tr}$ & $(951 \pm 5)^{\mathrm{c}}$ & $(0.63 \pm 0.01)^{c}$ & $(2.39 \pm 0.01)^{\mathrm{c}}$ & $(60 \pm 0)^{a}$ \\
\hline \multicolumn{9}{|l|}{ Variety } \\
\hline Altess & $(3 \pm 1)^{\mathrm{a}}$ & $(314 \pm 3)^{a}$ & $(486 \pm 4)^{a}$ & $(1.0 \pm 0.1)^{\mathrm{a}}$ & $(804 \pm 6)^{a}$ & $(0.86 \pm 0.02)^{\mathrm{a}}$ & $(2.78 \pm 0.02)^{\mathrm{a}}$ & $(59 \pm 0)^{\mathrm{a}}$ \\
\hline Biltstar & $(1 \pm 1)^{\mathrm{a}}$ & $(322 \pm 3)^{\mathrm{a}}$ & $(612 \pm 4)^{\mathrm{b}}$ & tr & $(936 \pm 6)^{b}$ & $(0.23 \pm 0.02)^{\mathrm{b}}$ & $(1.74 \pm 0.02)^{\mathrm{b}}$ & $(66 \pm 0)^{\mathrm{b}}$ \\
\hline Niagara & $(2 \pm 1)^{\mathrm{a}}$ & $(295 \pm 3)^{b}$ & $(509 \pm 4)^{c}$ & $\operatorname{tr}$ & $(807 \pm 6)^{a}$ & $(0.34 \pm 0.02)^{\mathrm{c}}$ & $(1.76 \pm 0.02)^{\mathrm{b}}$ & $(63 \pm 0)^{c}$ \\
\hline Oliwin & $(7 \pm 1)^{\mathrm{b}}$ & $(288 \pm 3)^{b}$ & $(480 \pm 4)^{\mathrm{a}}$ & $\operatorname{tr}$ & $(776 \pm 6)^{c}$ & $(0.31 \pm 0.02)^{c}$ & $(1.02 \pm 0.02)^{c}$ & $(58 \pm 0)^{\mathrm{d}}$ \\
\hline \multicolumn{9}{|l|}{ Type of pressing } \\
\hline Cold-pressed & $(3 \pm 1)^{a}$ & $(318 \pm 2)^{a}$ & $(518 \pm 3)^{a}$ & $\operatorname{tr}$ & $(840 \pm 4)^{\mathrm{a}}$ & $(0.35 \pm 0.01)^{\mathrm{a}}$ & $(1.78 \pm 0.01)^{\mathrm{a}}$ & $(61 \pm 0)^{\mathrm{a}}$ \\
\hline Conditioning $30 \mathrm{~min} / 60^{\circ} \mathrm{C}$ & $(4 \pm 1)^{\mathrm{a}}$ & $(292 \pm 2)^{b}$ & $(525 \pm 3)^{b}$ & $(1.0 \pm 0.1)^{\mathrm{b}}$ & $(821 \pm 4)^{b}$ & $(0.52 \pm 0.01)^{\mathrm{b}}$ & $(1.87 \pm 0.01)^{\mathrm{b}}$ & $(62 \pm 0)^{\mathrm{b}}$ \\
\hline Grand mean value ${ }^{*}$ & $(3 \pm 1)$ & $(305 \pm 2)$ & $(522 \pm 2)$ & $(0.44 \pm 0.04)$ & $(801 \pm 3)$ & $(0.43 \pm 0.10)$ & $(1.83 \pm 0.01)$ & $(62 \pm 1)$ \\
\hline
\end{tabular}

The results are expressed as mean value \pm standard error. Different letters in superscript in the same column indicate significant differences $(\mathrm{p}<0.05)$; $\mathrm{tr}=$ trace $(<0.1)$ in statistical analysis was set to 0 .

${ }^{1}$ Expressed as pheophytin a, ${ }^{2}$ expressed as $\beta$-carotene

*Total average per column

examined variable we calculated an optimal value to determine which particular climate parameters (that are function of climate index from Eqs. 4-6) have the strongest influence on the antioxidant activity measured with the percentage of DPPH reduction. Optimal value is the highest or lowest mathematical extremum obtained with response surface methodology (RSM) for single mathematical function that takes into account three variables: $(i)$ one of the studied variables (content of $\alpha$-tocopherol, plastochromanol-8, $\gamma$-tocopherol, $\delta$-tocopherol, total tocopherols, chlorophyll and carotenoids), (ii) the percentage of reduced DPPH, and (iii) climate index (that can be converted to temperature, sunshine and rainfall with Eqs. $4-6$ ). This number gives the highest ( $\alpha$-tocopherol, plastochromanol-8, $\gamma$-tocopherol, total tocopherol and carotenoid) or lowest ( $\delta$-tocopherol and chlorophyll) concentration of a particular biologically active compound and answers under which combination of climate parameters such extremum will be obtained $(6,7)$.

\section{Content of $\gamma$-tocopherol}

In the analyzed samples, the most abundant tocochromanol, including plastochromanol-8, was $\gamma$-tocopherol. Grand mean value of $\gamma$-tocopherol in the study was $(522 \pm 2) \mathrm{mg}$ per $\mathrm{kg}$ of oil (Table 1$)$ or $63 \%$ of total tocochromanols. Previously published results were $(800 \pm 0)$ and $(370 \pm 0) \mathrm{mg}$ per $\mathrm{kg}$ of cold-pressed flaxseed oil $(20,21)$. Similar average results were obtained by organic solvent extraction at $(322 \pm 2),(403 \pm 42),(542 \pm 36)$ and $(757 \pm 13) \mathrm{mg}$ per $\mathrm{kg}$ of oil $(7,22-24)$. Choo et al. (1) reported much lower values of $\gamma$-tocopherol with mean value of $(124 \pm 15) \mathrm{mg}$ per $\mathrm{kg}$ of oil. However, the authors obtained their samples from bottled oil from shops, while others analyzed freshly pressed or extracted oil. Therefore, the mass fraction of tocochromanols linearly decreased due to prolonged oxidation during undefined storage time (1). Other published papers on flaxseed oil produced from toasted flaxseeds (9) or by pressing flaxseed under elevated temperature $\left(80-120^{\circ} \mathrm{C}\right)(10)$ did not report results for tocochromanols.

Harvesting year significantly affected the amounts of $\gamma$-tocopherol, thus the lowest amount of $\gamma$-tocopherol was determined in 2011 and the highest in 2013 (Table 1). This can be explained by the influence of climate (Fig. 1), where the mass fraction of $\gamma$-tocopherol increased with average temperature and total sunshine during seed maturation. However, $\gamma$-tocopherol showed no association with the total rainfall during seed maturation (Table 2).

Changes in $\gamma$-tocopherol content and antioxidant capacity in relation to climate index are shown in Table 2. Climate index identified the optimal yield of a particular tocochromanol in relation to all climate factors of interest while retaining all of their mutual relations. Hence, Table 2 shows that increase of temperature and sunshine resulted in the increase of $\gamma$-tocopherol with analogous increase of antioxidant capacity. On the contrary, increase of rainfall decreases the $\gamma$-tocopherol content and antioxidant capacity. All but for rainfall, relations were in agreement with Pearson's correlations from Table 2. Optimal mass fraction of $\gamma$-tocopherol is $707 \mathrm{mg}$ per $\mathrm{kg}$ of oil at climate index 0.1982 which was converted with Eqs. 4-6 to average daily temperature of $23^{\circ} \mathrm{C}$, daily sunshine of $10.4 \mathrm{~h}$ and average daily rainfall of $1.7 \mathrm{~mm}$. This combination of calculated climate conditions was best achieved during the 5 th week of flaxseed maturation. The research by Herchi et al. (6) also identified the 5th week of maturation as 
Table 2. Correlation coefficients of tocochromanols, pigments and climate factors from flowering to harvesting, and the percentage of $\mathrm{DPPH}$ reduction

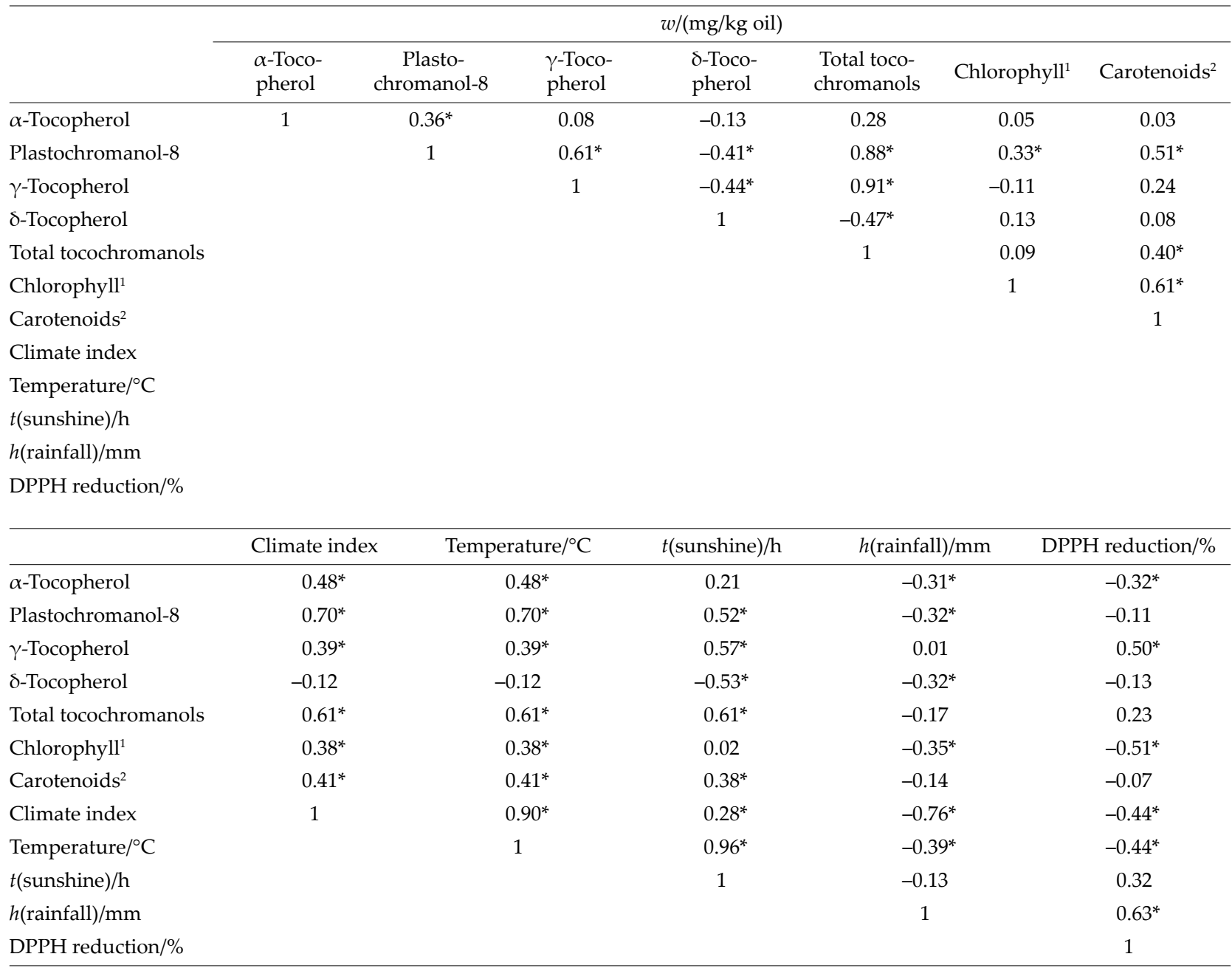

${ }^{1}$ Expressed as pheophytin a, ${ }^{2}$ expressed as $\beta$-carotene; ${ }^{*}$ correlation is significant at the level of 0.05 (2-tailed)

the period with maximum level of oil in flaxseed, after which biosynthesis gradually slowed down and slightly declined before harvesting. In their another work, the 5th week was associated with second most intensive increase in $\gamma$-tocopherol levels (other was 2nd week of maturation) (7).

Biltstar variety had the highest mass fraction of $\gamma$-tocopherol, while the lowest were detected in Altess and Oliwin, and if flaxseed was pressed after conditioning, it had higher content of $\gamma$-tocopherol (Table 1).

In conclusion, our results for $\gamma$-tocopherol are similar to other literature findings and show that increased content of $\gamma$-tocopherol was the result of increased warmth, sunshine and conditioning of flaxseeds before oil extraction (6).

\section{Plastochromanol-8 content in oil}

Second most represented tocochromanol in our samples was plastochromanol-8. Mean average value was $(305 \pm 2) \mathrm{mg}$ per $\mathrm{kg}$ of oil (Table 1 ) or $37 \%$ of all tocochromanols. Varieties Altess and Biltstar had the highest mass fractions of plastochromanol-8 and the cold-pressed oil had more plastochromanol-8 in comparison with the oil from conditioned seeds (Table 1). Plastochromanol-8 is considered to be a natural homologue of $\gamma$-tocotrienol that contains a longer side chain (3). Apart from flaxseed, where it is abundantly represented, it can be found in smaller quantities in a variety of oilseeds like rapeseed, mustard, soya bean or camelina (25). Recent studies by Ciftci et al. (23) reported plastochromanol-8 values of $(191 \pm 12) \mathrm{mg}$ per $\mathrm{kg}$ of oil or $26 \%$ of all tocochromanols. Results by Gruszka and Kruk (25) reported the average value of $(217 \pm 5) \mathrm{mg}$ of plastochromanol-8 per $\mathrm{kg}$ of oil or about $46 \%$ of all tocochromanols.

Similarly to $\gamma$-tocopherol, the content of plastochromanol-8 was the highest in 2013 (Table 1), when it strongly increased with average temperature and total sunshine during seed maturation (Fig. 1), while it moderately decreased with rainfall during seed maturation (confirmed by significant correlations from Table 2). These results imply that biosynthesis of two major tocochromanols in flaxseed oil is highly associated with climate. As documented by Kruk et al. (26) in Arabidopsis leaves, plastochromanol-8 increases from $38 \%$ under low-light up to 50 

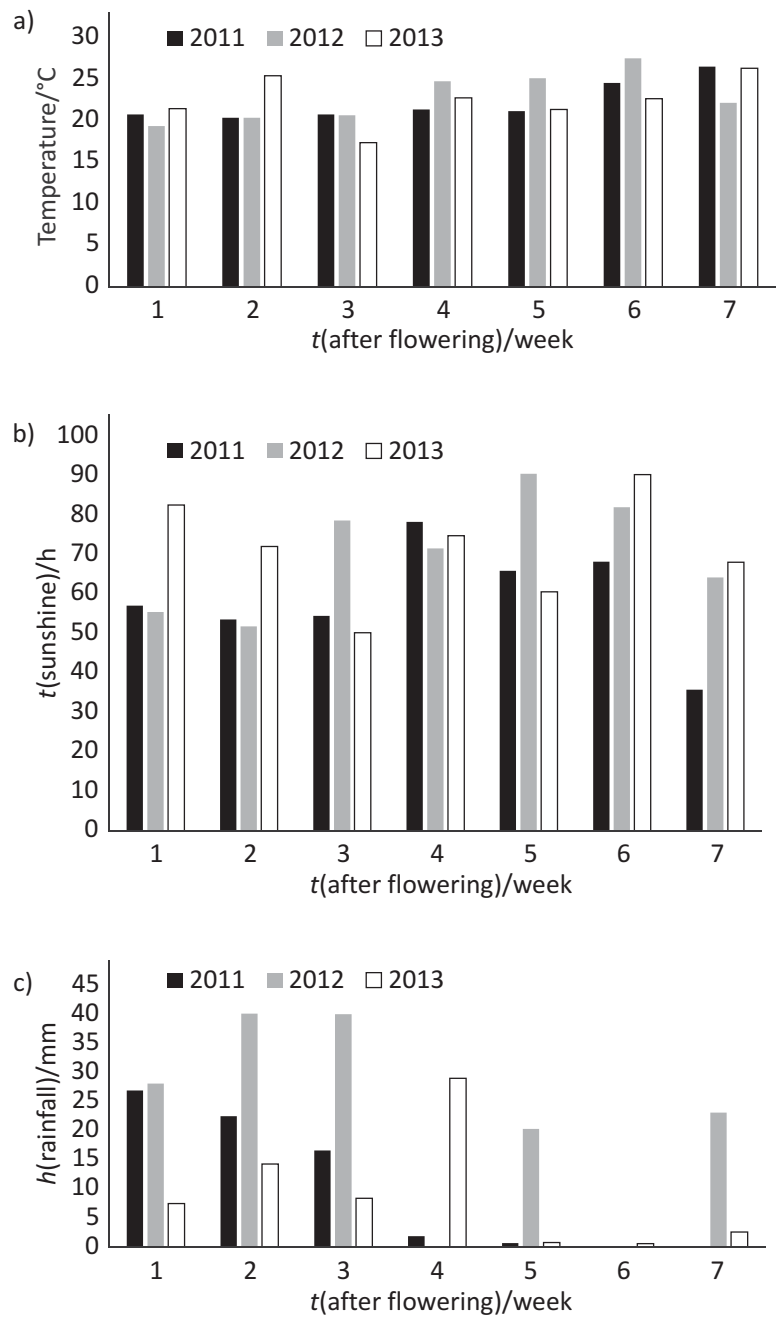

Fig 1. Environmental data for Zagreb, Croatia $\left(45^{\circ} 49^{\prime} 00^{\prime \prime} \mathrm{N}\right.$, $16^{\circ} 02^{\prime} 00^{\prime \prime}$ E): a) average weekly temperature, b) total weekly sunshine, c) average weekly rainfall

$\%$ under high-light conditions. Plastochromanol-8 had higher values in cold-pressed flaxseed oil (Table 1).

Results in Table 2 show that the increase of temperature and sunshine resulted in the increase of plastochromanol-8 with analogous increase of antioxidant capacity. On the contrary, increase of rainfall decreased the plastochromanol-8 content and antioxidant capacity (all but the percentage of reduced DPPH correlations were confirmed by Table 2). Optimal value of plastochromanol-8 was 392 $\mathrm{mg}$ per $\mathrm{kg}$ of oil at climate index 0.1982. As with $\gamma$-tocopherol, climate index conversion yielded average daily temperature of $23^{\circ} \mathrm{C}$, daily sunshine of $10.4 \mathrm{~h}$ and average daily rainfall of $1.7 \mathrm{~mm}$, all achieved during the 5th week of flaxseed maturation. Herchi et al. (6) also identified the 5th week of maturation with second most intensive increase in plastochromanol-8 levels (other was 3rd week of maturation) (7).

\section{Content of $\alpha$-tocopherol}

Mass fraction of $\alpha$-tocopherol in the samples was much lower in comparison with other major tocochromanols. The grand mean value in our samples was $(3 \pm 1)$ mg per kg of oil (Table 1) or $0.4 \%$ of total tocochromanols. Harvesting year significantly affected the mass fraction of $\alpha$-tocopherol and, as with other tocochromanols, we detected significantly higher amounts of this tocochromanol in the year 2013 (Table 1). Oliwin variety had the highest mass fraction of $\alpha$-tocopherol, while Altess, Biltstar and Niagara had similarly low mass fractions of this compound. During seed maturation, levels of $\alpha$-tocopherol increased with the increase of average temperature and decreased with the increase of rainfall (Table 2). Type of pressing had no significant effect on the levels of $\alpha$-tocopherol (Table 1). Accordant with our results, reported average levels of $\alpha$-tocopherol in flaxseed oil obtained from organic solvent extraction were much lower than of other tocochromanols and were from $(6 \pm 1)$ to $(16 \pm 0) \mathrm{mg}$ per $\mathrm{kg}$ of oil $(2,7,22,23)$, with only one exception of $40 \mathrm{mg}$ per $\mathrm{kg}$ of oil (20). Similarly high variations between the values of $\alpha$-tocopherol were found in shea butter (4) and camelina oil samples (27) influenced by variety and region of harvesting.

Results in Table 2 show that increase of temperature and sunshine is followed by increase of $\alpha$-tocopherol with analogous increase of antioxidant capacity. On the contrary, increase of rainfall decreases $\alpha$-tocopherol content and antioxidative capacity (Table 2). Similar to other tocochromanols, optimal mass fraction of $\alpha$-tocopherol was 9 mg per $\mathrm{kg}$ of oil with climate index of 0.1982 (average daily temperature of $23^{\circ} \mathrm{C}$, daily sunshine of $10.4 \mathrm{~h}$ and average daily rainfall of $1.7 \mathrm{~mm}$ detected in the 5th week of flaxseed maturation). In research on $\alpha$-tocopherol in soya bean large increase was noted at higher temperature and drought combined with decrease in $\gamma$ - and $\delta$-tocopherol (28). From biosynthetic pathway presented by Mène-Saffrané and DellaPenna (29) we can see that 2-methyl-6-phytyl-benzoquinol (MPBQ) is a shared substrate for the synthesis of both $\gamma$ - and $\delta$-tocopherol. It appears that higher temperature and lack of rainfall forces plants to go one step further in the synthesis of $\alpha$-tocopherol to prevent oxidative damage under stress conditions. In response to high light conditions, wild-type plants accumulate only $\alpha$-tocopherolquinol, a product of $\alpha$-tocopherol oxidation (29). Based on this we can hypothesize that $\alpha$-tocopherol is an antioxidant synthesized in flaxseed mostly in extreme conditions, while increased amounts of $\alpha$-tocopherol added to preserve flaxseed oil can act as prooxidants as shown in research by Bravi et al. (30).

\section{Presence of $\delta$-tocopherol}

$\delta$-Tocopherol was detected in the lowest amounts of all tocochromanols. The grand mean value in our samples was $0.4 \mathrm{mg}$ per $\mathrm{kg}$ of oil or $0.05 \%$ of total tocochromanols (Table 1). The presence of $\delta$-tocopherol in the analyzed oil samples was found only in the samples from 2011. Only one sample of oil of Altess variety produced after conditioning had $(1.0 \pm 0.1) \mathrm{mg}$ of $\delta$-tocopherol per $\mathrm{kg}$ of oil (Table 1). Previous results obtained by organic solvent extraction reported mass fractions of $\delta$-tocopherol of $(5 \pm 1)$, $(19 \pm 0)$ and $(23 \pm 0) \mathrm{mg}$ per $\mathrm{kg}$ of oil $(2,23,24)$.

Contrary to other tocochromanols, the mass fraction of $\delta$-tocopherol decreased under higher sunshine and higher rainfall conditions during seed maturation but showed no association with average temperature (Table 
2). Britz and Kremer (28) reported the decrease of $\delta$-tocopherol under the influence of higher temperature during maturation of soya beans. Correlation between $\gamma$-tocopherol, plastochromanol-8 and $\delta$-tocopherol showed significant increase of $\gamma$-tocopherol/plastochromanol-8 content with decrease of $\delta$-tocopherol (Table 2). Pathways for biosynthesis of all tocochromanols were widely investigated in Arabidopsis plants and are initiated by the conversion of $p$-hydroxyphenylpyruvic acid (HPP) into homogentisic acid (HGA). Condensation of HGA and phytyl pyrophosphate results in the formation of 2-methyl-6-phytyl-benzoquinol (MPBQ), the starting intermediate of all tocochromanols. HGA biosynthesis leads to two parallel pathways, one forming plastochromanol-8 and the other branching in two subpathways for $\delta$-tocopherol and $\gamma$-tocopherol, which can explain why there is inverse correlation between plastochromanol- $8 / \gamma$-tocopherol vs. $\delta$-tocopherol (29).

Results in Table 2 show that decrease of sunshine and of rainfall results in the increase of $\delta$-tocopherol with analogous decrease of antioxidant capacity. Accordingly, a relationship between sunshine and rainfall can be seen in Table 2 but not between temperature and antioxidant capacity (likely due to overall small quantities of $\delta$-tocopherol in the study). Optimal mass fraction of $\delta$-tocopherol is $1 \mathrm{mg}$ per $\mathrm{kg}$ of oil at climate index of -0.15 , which is converted with Eqs. 4-6 to average daily temperature of 22 ${ }^{\circ} \mathrm{C}$, daily sunshine of $9.8 \mathrm{~h}$ and average daily rainfall of $2.1 \mathrm{~mm}$. Combination of calculated climate conditions was best achieved during the first two weeks of flaxseed maturation. These results possibly identify $\delta$-tocopherol as an important antioxidant during earlier stages of seed development or during lower temperatures, while its biosynthetic pathway is not active during later phases when this tocopherol is lost.

\section{Total tocochromanols}

The grand mean value of total tocochromanol in our samples was $(831 \pm 3) \mathrm{mg}$ per $\mathrm{kg}$ of oil (Table 1$)$. Total tocochromanols differed in harvesting years in range from $(727 \pm 5)$ to $(956 \pm 5) \mathrm{mg}$ per $\mathrm{kg}$ of oil. The samples from 2011 had the lowest, while those from 2013 had the highest mass fraction of total tocochromanols (Table 1). Mass fraction of total tocochromanols strongly increased with the increase of average temperature and sunshine, without association with the quantity of the rainfall during seed maturation (Table 2). This result is in agreement with literature findings where it is shown that increased temperature results in the increase of total tocochromanols during maturation of canola, soya bean, oat and shea seeds (4). Average value of total tocochromanols in cold-pressed flaxseed oil was reported to be from $(182 \pm 11)$ (1) to $(840 \pm$ 15) $\mathrm{mg}$ per $\mathrm{kg}$ of oil (20). As stated for $\gamma$-tocopherol, the levels of total tocochromanols in samples analyzed by Choo et al. (1) were probably low because of oxidation during prolonged storage in shops. Oil obtained by the extraction with organic solvent had values of tocochromanols of $(347 \pm 3),(534 \pm 95),(747 \pm 48),(794 \pm 13)$ and $(934 \pm 2)$ mg per $\mathrm{kg}$ of oil $(2,7,22-24)$.

Table 2 shows that increase of temperature and sunshine results in the increase of the total content of tocochromanols with analogous increase of antioxidant capacity. On the contrary, increase of rainfall decreases the tocochromanol content and antioxidant capacity. Relationship between sunshine and temperature can be seen in Table 2, but not that between rainfall and antioxidant activity. Optimal mass fraction of total tocochromanol is $1104 \mathrm{mg}$ per $\mathrm{kg}$ at climate index of 0.1982 (converted to temperature of $23{ }^{\circ} \mathrm{C}$, sunshine of $10.4 \mathrm{~h}$, and rainfall of $1.7 \mathrm{~mm}$, achieved in the 5th week of flaxseed maturation). Biltstar variety had the highest mass fraction of total tocochromanols, while the lowest mass fraction was detected in Oliwin. Cold pressing yielded more of this group of compounds in comparison with oil from conditioned seeds (Table 1).

\section{Carotenoid content in oil samples}

The grand mean value of carotenoids expressed as $\beta$-carotene was $(1.83 \pm 0.01) \mathrm{mg}$ per $\mathrm{kg}$ of oil (Table 1$)$. Depending on the harvesting year, carotenoids ranged from $(1.39 \pm 0.01)$ to $(2.40 \pm 0.01) \mathrm{mg}$ per $\mathrm{kg}$ of oil (Table 1$)$. Similar results had previously been published and varied from $(0.7 \pm 0.10)$ to $(3.10 \pm 0.46) \mathrm{mg}$ per $\mathrm{kg}$ of oil $(7,31)$. As with majority of tocochromanols, the highest mass fractions of carotenoids were determined in year 2013. Average temperature and sunshine during seed maturation significantly correlated with the increase in the mass fraction of carotenoids (Table 2). This was expected as carotenoids accumulated in plant seeds are important for protection of triacylglycerols, unsaturated lipids, membranes and phenol quinones from photooxidation (7). Altess variety had the highest, and Oliwin had the lowest mass fractions of carotenoids (Table 1). If flaxseeds were conditioned, their oil had more carotenoids. The higher carotenoid content in the oil from conditioned seeds may be partially explained by the prolonged contact time of the oil released during conditioning with the rest of the seed, which may improve pigment extraction into the oil.

In Table 2 we can see that the increase of temperature and sunshine resulted in the increase of carotenoids with analogous increase of antioxidant capacity. On the contrary, increase of rainfall decreases carotenoid content and antioxidant capacity. These relationships were further confirmed (except for rainfall) by Pearson's correlations in Table 2. Optimal content of carotenoids was 2.57 mg per $\mathrm{kg}$ of oil at climate index of 0.1982 , which was converted using Eqs. 4-6 equals to temperature of $23^{\circ} \mathrm{C}$, sunshine of $10.4 \mathrm{~h}$ and rainfall of $1.7 \mathrm{~mm}$. This combination of calculated climate conditions was best achieved during the 5 th week of flaxseed maturation.

\section{Chlorophyll content in oil samples}

The chlorophyll mean average value expressed as pheophytin a was $(0.44 \pm 0.10) \mathrm{mg}$ per $\mathrm{kg}$ of oil (Table 1$)$. Mean chlorophyll levels varied with year from $(0.24 \pm 0.01)$ to $(0.63 \pm 0.01) \mathrm{mg}$ per $\mathrm{kg}$ of oil, which is less than previously reported from $(2.99 \pm 0.17)$ to $(3.40 \pm 0.10) \mathrm{mg}$ per $\mathrm{kg}$ of oil $(7,31)$. Again, we found the highest content of chlorophyll in year 2013, while variety Altess had the highest levels of this pigment (Table 1). Levels of chlorophyll slightly increased with average temperature and slightly decreased with rainfall during seed maturation (Table 2). DellaPenna and Pogson (8) reported inverse correlations between chlorophyll and tocopherols, but we determined different relationship with plastochromanol-8. Positive correlation between the levels of plastochromanol-8, ca- 
rotenoids and chlorophyll with the increase in sunshine singles out these compounds as important molecules in seeds during high UV index (Table 2). Conditioning of seeds resulted in higher yield of chlorophyll (Table 1).

\section{DPPH radical scavenging activity of flaxseed oil}

To measure the antioxidant activity in oil we determined free radical scavenging activity. The grand mean value of DPPH reduction in all samples was $(62 \pm 1) \%$ (Table 1). All produced oil samples had values between $(59 \pm 0)$ and $(66 \pm 0) \%$ of reduced DPPH depending on the harvest year (Table 1). Oil from Biltstar variety had the highest, and from Altess the lowest scavenging activity. Cold-pressed oil and those from conditioned seeds showed very similar antioxidant activity (Table 1 ). The strongest correlation between the percentage of reduced DPPH and the content of tocochromanols was shown in the results for $\gamma$-tocopherol (Table 2); with increased mass fraction of $\gamma$-tocopherol in the oil, the antioxidant activity significantly increased. Contrarily, the content of $\alpha$-tocopherol and chlorophyll decreased as antioxidant activity increased (Table 2). Biltstar variety had the highest, while the oil from varieties Altess and Olwin had the lowest content of $\gamma$-tocopherol. This was more noticable during colder periods of seed maturation and could be connected with antioxidant activity in earlier phases of seed development. Contrary to some other reports (3), the level of plastochromanol-8 did not show significant correlations with antioxidant activity.

\section{Conclusions}

Comparative results of four flaxseed varieties distinguished the cold-pressed oil from Biltstar variety as the best source of natural tocochromanols with strongest antioxidant activity. Along with the choice of variety, significant influence of climate during seed development was noted. Cold-pressed oil had higher levels of total tocochromanols but showed similar antioxidant activity. The main representative of the group of tocols, $\gamma$-tocopherol, was most abundant in Biltstar variety and had strong positive correlation with average temperature and total sunshine, and negative correlation with total rainfall during seed maturation. Plastochromanol-8, characteristic tocochromanol in flaxseed oil, showed similar relationship with climatic influences but did not show significance in relation to antioxidant activity. Further research is needed to provide the best explanations about possible protective role of plastochromanol-8 in flaxseed oil. Contents of $\alpha$ and $\delta$-tocopherols were very low, while $\delta$-tocopherol was the only tocol which had negative correlation with both average temperature and sunshine during seed maturation. Altess variety had the highest level of pigments. While the level of carotenoids had no significant influence, chlorophyll content had strongly negative correlation with antioxidant activity.

\section{Acknowledgements}

The present study was supported by the Ministry of Science, Education and Sports of the Republic of Croatia (project no. 058-0580696-0704).

\section{References}

1. Choo WS, Birch J, Dufour JP. Physicochemical and quality characteristics of cold-pressed flaxseed oils. J Food Compos Anal. 2007;20:202-11. http://dx.doi.org/10.1016/j.jfca.2006.12.002

2. Oomah BD, Kenaschuk EO, Mazza G. Tocopherols in flaxseed. J Agric Food Chem. 1997;45:2076-80.

http://dx.doi.org/10.1021/jf960735g

3. Siger A, Kachlicki P, Czubiński J, Polcyn D, Dwiecki K, Nogala-Kalucka M. Isolation and purification of plastochromanol-8 for HPLC quantitative determinations. Eur J Lipid Sci Tech. 2014;116:413-22. http://dx.doi.org/10.1002/ejlt.201300297

4. Maranz S, Wiesman Z. Influence of climate on the tocopherol content of shea butter. J Agric Food Chem. 2004;52:2934-37. http://dx.doi.org/10.1021/jf035194r

5. Tura D, Gigliotti C, Pedò S, Failla O, Bassi D, Serraiocco A. Influence of cultivar and site of cultivation on levels of lipophilic and hydrophilic antioxidants in virgin olive oils (Olea Europea L.) and correlations with oxidative stability. Sci Hortic. 2007;112:108-19. http://dx.doi.org/10.1016/j.scienta.2006.12.036

6. Herchi W, Bouali I, Bahashwan S, Rochut S, Boukhchin S, Kallel H, Pepe C. Changes in phospholipid composition, protein content and chemical properties of flaxseed oil during development. Plant Physiol Biochem. 2012;54:1-5.

http://dx.doi.org/10.1016/j.plaphy.2012.02.008

7. Herchi W, Sakouhi F, Boukhchina S, Kallel H, Pepe C. Changes in fatty acids, tocochromanols, carotenoids and chlorophylls content during flaxseed development. J Am Oil Chem Soc. 2011;88:1011-7. http://dx.doi.org/10.1007/s11746-010-1750-3

8. DellaPenna D, Pogson BJ. Vitamin synthesis in plants: tocopherols and carotenoids. Annu Rev Plant Biol. 2006;57: 711-38. http://dx.doi.org/10.1146/annurev.arplant.56.032604.144301

9. Epaminondas PS, Araújo KLGV, Nascimento JA, Silva MCD, Rosenhaim R, Soledade LEB, et al. Influence of toasting and the seed variety on the physico-chemical and thermo-oxidative characteristics of the flaxseed oil. J Therm Anal Calorim. 2011;106:545-50.

http://dx.doi.org/10.1007/s10973-011-1731-2

10. Mridula D, Barnwal P, Singh KK. Screw pressing performance of whole and dehulled flaxseed and some physicochemical characteristics of flaxseed oil. J Food Sci Tech Mys. 2015;52:1498-506. http://dx.doi.org/10.1007/s13197-013-1132-6

11. FAOSTAT Statistics Division, Food and Agriculture Organization of the United Nations, Rome, Italy. Available from: http://faostat.fao.org.

12. Flax, Oilseed-List of varieties which are registered in Canada, Canadian Food Inspection Agency, Ottawa, ON, Canada. Available from: http://www.inspection.gc.ca.

13. Plant variety catalogues and databases, European Commission, Bruxelles, EU. Available from: http://ec.europa.eu/food/ plant/propagation/catalogues/agri2011/68.html.

14. Reboredo-Rodriguez P, González-Barreiro C, Cancho-Grande B, Fregapane G, Salvador MD, Simal-Gándara J. Characterisation of extra virgin olive oils from Galician autochthonous varieties and their co-crushings with Arbequina and Picual cv. Food Chem. 2015;176:493-503.

http://dx.doi.org/10.1016/j.foodchem.2014.12.078

15. Food and Agriculture Organization of the United Nations and World Health Organization, Codex Standard for Named Vegetable Oils, 2011, FAO/WHO: Rome. 
16. ISO 9936:2006. Animal and vegetable fats and oils - Determination of tocopherol and tocotrienol contents by high-performance liquid chromatography. Geneva, Switzerland: International Organization for Standardization (ISO); 2006.

17. Pokorny J, Kalinova L, Dysseler P. Determination of chlorophyll pigments in crude vegetable oils: results of a collaborative study and the standardized method (technical report). Pure Appl Chem. 1995;67:1781-7. http://dx.doi.org/10.1351/pac199567101781

18. BS method 684-2-20:1977. Methods of analysis of fats and fatty oils. Other methods. Determination of carotene in vegetable oils. London, UK: British Standards Institution; 1976.

19. Kalantzakis G, Blekas G, Pegklidou K, Boskou D. Stability and radical-scavenging activity of heated olive oil and other vegetable oils. Eur J Lipid Sci Tech. 2006;108:329-35. http://dx.doi.org/10.1002/ejlt.200500314

20. Abuzaytoun R, Shahidi F. Oxidative stability of flax and hemp oils. J Am Oil Chem Soc. 2006;83:855-61. http://dx.doi.org/10.1007/s11746-006-5037-7

21. Teh SS, Birch J. Physicochemical and quality characteristics of cold-pressed hemp, flax and canola seed oils. J Food Compos Anal. 2013;30:26-31. http://dx.doi.org/10.1016/j.jfca.2013.01.004

22. Bozan B, Temelli F. Chemical composition and oxidative stability of flax, safflower and poppy seed and seed oils. Bioresour Technol. 2008;99:6354-9. http://dx.doi.org/10.1016/j.biortech.2007.12.009

23. Ciftci ON, Przybylski R, Rudzińska M. Lipid components of flax, perilla, and chia seeds. Eur J Lipid Sci Tech. 2012;114: 794-800. http://dx.doi.org/10.1002/ejlt.201100207

24. Khattab RY, Zeitoun MA. Quality evaluation of flaxseed oil obtained by different extraction techniques. LWT - Food Sci
Technol. 2013;53:338-45.

http://dx.doi.org/10.1016/j.lwt.2013.01.004

25. Gruszka J, Kruk J. RP-LC for determination of plastochromanol, tocotrienols and tocopherols in plant oils. Chromatographia. 2007;66:909-13. http://dx.doi.org/10.1365/s10337-007-0416-2

26. Kruk J, Szymańska R, Cela J, Munne-Bosch S. Plastochromanol-8: fifty years of research. Phytochemistry. 2014;108:9-16. http://dx.doi.org/10.1016/j.phytochem.2014.09.011

27. Zubr J, Matthäus B. Effects of growth conditions on fatty acids and tocopherols in Camelina sativa oil. Ind Crop Prod. 2002; 15:155-62. http://dx.doi.org/10.1016/S0926-6690(01)00106-6

28. Britz SJ, Kremer DF. Warm temperatures or drought during seed maturation increase free $\alpha$-tocopherol in seeds of soybean (Glycine max [L.] Merr.). J Agric Food Chem. 2002;50: 6058-63. http://dx.doi.org/10.1021/jf0200016

29. Mène-Saffrané L, DellaPenna D. Biosynthesis, regulation and functions of tocochromanols in plants. Plant Physiol Biochem. 2010;48:301-9. http://dx.doi.org/10.1016/j.plaphy.2009.11.004

30. Bravi E, Perretti G, Marconi O, Patrizi E, Fantozzi P. Secoisolariciresinol diglucoside determination in flaxseed (Linum usitatissimum L.) oil and application to a shelf life study. Food Chem. 2011;126:1553-8. http://dx.doi.org/10.1016/j.foodchem.2010.11.169

31. Tuberoso CIG, Kowalczyk A, Sarritzu E, Cabras P. Determination of antioxidant compounds and antioxidant activity in commercial oilseeds for food use. Food Chem. 2007;103:1494501. http://dx.doi.org/10.1016/j.foodchem.2006.08.014 